\title{
КОМПАРАТОР ГОСУДАРСТВЕННОГО СЕКТОРА КАК ОСНОВНОЙ ЭЛЕМЕНТ ОЦЕНКИ СРАВНИТЕЛЬНОГО ПРЕИМУЩЕСТВА ПРОЕКТОВ ГЧП: ОПЫТ ВЕЛИКОБРИТАНИИ
}

\section{PUBLIC SECTOR COMPARATOR \\ AS THE MAIN ELEMENT \\ OF THE ASSESSMENT COMPARATIVE ADVANTAGE OF PPP PROJECTS: UK EXPERIENCE}

\section{O. Trotsenko}

Summary. Assessment of the comparative advantage of public-private partnership projects is based on quantitative and qualitative analyzes. A quantitative analysis of a PPP project includes a comparison of the price-quality ratio in the proposed PPP project and in its implementation through traditional public procurement, based on the application of the Public Sector Comparator methodology (calculating the price of a similar project through direct budget financing). The article examines the practice of using a public sector comparator on the example of British PPP projects, identifies its advantages and disadvantages.

Keywords: comparator, comparative advantage assessment, publicprivate partnership, public partner, private partner, private financial initiative, public-private partnership agreement.

\author{
троценко Оксана Сергеевна \\ К.ю.н., дочент, Уральский государственный \\ экономический университет \\ trocenko.o@mail.ru
}

Аннотация. Оценка сравнительного преимущества проектов государственно-частного партнерства (далее - ГЧП) основывается на количественном и качественном анализах. Количественный анализ проекта включает в себя сравнение соотношения цены и качества в предлагаемом проекте ГЧП и при его реализации через традиционные государственные закупки, основанное на применении методологии Public Sector Comparator расчет цены аналогичного проекта через прямое бюджетное финансирование. В статье рассматривается практика применения компаратора государственного сектора на примере британских проектов ГЧП, выявляются ее преимущества и недостатки.

Ключевые слова: компаратор, оценка сравнительного преимущества, государственно-частное партнерство, публичный партнер, частный партнер, частная финансовая инициатива, соглашение о государственно-частном партнерстве.
$\mathbf{M}$ еханизм определения сравнительного преимущества и оценки эффективности проектов ГЧП, заложенный в Федеральном законе от 13 июля 2015 года № 224-Ф3 «О государственно-частном-партнерстве, муниципально-частном партнерстве в Российской Федерации и внесении изменений в отдельные законодательные акты Российской Федерации» [12] (далее - Закон о ГЧП) и отсутствующий в Федеральном законе от 21 июля 2005 года № 115-Ф3 «О концессионных соглашениях» [13] (далее - Закон о концессионных соглашениях), вызывает большое количество вопросов и на практике становится серьезным препятствием для привлечения частных инвестиций в крупные инфраструктурные проекты. Так, по справедливому замечанию А.В. Белицкой, «сравнительное преимущество должно убедительно доказывать, что для государственного бюджета будет менее затратным реализовать публичный интерес посредством осуществления инвестиционного проекта в форме соглашения о государственно-частном партнерстве, чем реализовать тот же самый проект на основании государственного контракта» [10, с. 468]. Компаратор государственного сектора, public sector comparator (PSC), - это техническая конструкция, подробно описывающая все затраты государственного сектора, если проект реализуется традиционно. Компаратор государственного сектора, судя по зарубежному законодательству, используется правительством для принятия решений путем проверки инвестиционного предложения, предложения цены и качества, в сравнении с наиболее эффективной формой — государственными закупками [4].

PSC разрабатывается на предварительном этапе бизнес-фазы и должен быть завершен до заключения соглашения о ГЧП, т.е. на этапе разработки проекта. PSC обеспечивает анализ частной инициативы на предмет соотношения цена-качество. Он состоит из четырех компонентов (см. рис. 1).

\section{Компаратор госумарственного сектора}

Указанные компоненты начинаются с «начального компаратора» (капитальные и эксплуатационные расходы), который соответствует базовой стоимости оказания 


\begin{tabular}{|c|c|c|}
\hline $\begin{array}{l}\text { 1. Raw PSC (Capital and operating cost) } \\
\text { Капитальные и эксплуатационные } \\
\text { расходы }\end{array}$ & \multirow{2}{*}{$\begin{array}{c}\text { PUBLIC SECTOR COMPARATOR (PSC) } \\
\text { Компаратор государственного сектора }\end{array}$} & $\begin{array}{l}\text { 2. Competitive neutrality (Cost adjustment } \\
\text { to eliminate resource allocation distortion. } \\
\text { eg: Тах) } \\
\text { «Конкурентный нейтралитет» }\end{array}$ \\
\hline $\begin{array}{l}\text { 4. Retained risk (The value of those risks } \\
\text { which remain with the public sector) } \\
\text { Сохраняемый риск }\end{array}$ & & $\begin{array}{l}\text { 3. Transferable risk (Value of risk } \\
\text { transferable to the private sector) } \\
\text { Передаваемый риск }\end{array}$ \\
\hline
\end{tabular}

Рис. 1

услуг, названных в проектной документации к государственному контракту. Вторым следует «конкурентный нейтралитет», корректирующий затраты на устранение любых конкурентных преимуществ, которые получает государственный бизнес (страховая премия или налоги правительства). Третий - «передаваемый риск», который касается объема рисков, переходящих от публичного партнера к частному партнеру (риски на этапе проектирования и строительства, эксплуатационные и технологические риски). Наконец, четвертый риск «сохраняемый» - тот, который сохраняется за публичным партнером (риски спроса и безопасности).

Отметим, что компаратор в разных странах построен на различных подходах и методологиях. Так, в Великобритании компаратор является техническим средством, которое на основе анализа заданных параметров выдает оптимальное решение в выборе между ГЧП и государственным контрактом. ГЧП/ЧФИ можно рассматривать как с точки зрения права, так и с точки зрения государственного управления. Правовой аспект - это взаимные обязательства сторон, оплата за предоставленные товары и услуги; управленческий - соотношение цены и качества (VfM) и распределение рисков. Эти подходы имеют много общего: соотношение цена-качество выражается во взаимосвязи между ценой и предоставленными товарами и услугами; благодаря распределению рисков устанавливается связь между ценой и услугами: больше распределение рисков - выше цена. Сбалансированность цен, товары и услуги, соотношение цены и качества и распределение рисков - всё это компоненты сложности в ГЧП/ЧФИ. Правовые и экономические аспекты могут для обозначения одних и тех же реалий использовать разные концепты. Иными словами, товарно-денежный обмен - это способ согласования интересов государственных и частных сторон в правовом поле. Соотношение цены и качества и распределение рисков являются необходимыми для этого факторами.

В первую очередь, взаимные обязательства сторон по ГЧП/ЧФИ рассматриваются с точки зрения оплаты, затем - с учетом соотношения цена-качество и распределения рисков, в чем может быть полностью отражена рациональная максимизация вклада сторон. Однако, в отличие от идеализированного точного определения и количественной оценки обязательств сторон, практика ГЧП/ЧФИ являет собой более запутанную картину, когда отношения распределяются во времени и между разными участвующими сторонами, учитываются качественные факторы и создаются совместные механизмы управления. В условиях контракта формализация соотношения «цена-качество» и распределения рисков является лишь частичной; она находится за пределами договорных отношений, и договорные товарно-денежные отношения относятся, в основном, к процедурам управления перечисленными рисками, а не к важным решениям.

Согласно реляционной теории, благодаря контрактам, деловые связи развиваются во времени, выходящим за рамки анализируемых неоклассических договорных теорий. ГЧП/ЧФИ задают рамки долгосрочных обязательств, устанавливая стандарты оказания услуг и предмет договора на согласованный срок [5, с. 8]. Эти три элемента отражают то, как стороны понимают автономию и солидарность в ГЧП/ЧФИ. Основное же внимание уделяется оплате.

Оплата в ГЧП/ЧФИ может иметь разную форму. Особенно актуальным является то, как ГЧП/ЧФИ устроены вокруг «компании специального назначения» (SPV), coзданной для определенного проекта. Все финансовые потоки направлены только на этот конкретный проект. С данным SPV не связаны никакие ответственность или доходы, кроме тех, что рождаются из услуг или инфраструктуры, темпорально и географически ограниченных в договоре.

Таким образом, перекрестного субсидирования или солидарности с другими проектами (в интересах какой-либо из сторон) просто нет. Исходя из этого финансовые потоки можно сгруппировать следующим образом:

1. финансово независимые проекты;

2. транзакционные модели (например, SoPC4);

3. институциональная модель (например, PF2).

1. В финансово независимых проектах инвестиции частного сектора оплачиваются за счет сборов 
или платежей потребителей (физических лиц или корпораций, использующих данную услугу или инфраструктуру), а не государственным органом.

2. Модель SoPC4, главным образом, строится на механизме, в рамках которого государственный орган платит за активы и услуги. Транзакционная модель здесь более актуальна.

3. PF2 основывается на таком же принципе, что и SoPC4 - «нет услуги, нет оплаты» [8]. Однако финансовая инженерия, стоящая за проектными инвестициями, представляет собой сложный процесс, направленный на сбор инвестиций от более широкого круга участников. В SoPC4 частные подрядчики обеспечивают капитал посредством банковских займов. Цель PF2 состоит В привлечении капитала от институциональных инвесторов, среди которых пенсионные и страховые фонды.

Казначейство Великобритании определило критерии для оценки соотношения цены и качества в PFI (частная финансовая инициатива) и традиционных закупок с учетом долгосрочной потребности в объекте соглашения или закупок (продуктов, услуг) со стороны населения, эффективности управления рисками, в том числе со стороны частного партнера, брать на себя ответственность за доставку услуг конечному потребителю, обеспечения конкурентных торгов и т.д. Такая оценка является обязательной и осуществляется по модели Business Case Development - это общая британская методология оценки целесообразности государственных инвестиций, которая применяется как для проектов ГЧП, так и для других форм инвестиционных проектов с государственным участием. В Великобритании считается, что для оценки сравнительного преимущества необходимо учитывать также потенциальные нефинансовые параметры, в том числе синергетический эффект от реализации проекта, который может быть обеспечен за счет значительного накопленного опыта частного партнера в рамках управления комплексными проектами с учетом инновационных технологий [11].

Распределение рисков и управление рисками свидетельствуют о том, что риски имеют свою цену и подразделяются на государственный, частный или коллективный. Наличие рисков влечет за собой постановку следующих вопросов:

1. выявление рисков;

2. распределение рисков;

3. управление рисками.

Опыт Великобритании свидетельствует о том, что на практике ответить на указанные вопросы можно по-разному: выявление рисков связано с автономией в ГЧП, распределение рисков - с солидарностью, а управление рисками - с доверием. Процессы выявления - распределения - управления происходят в условиях дискреции и неопределенности, когда стороны пытаются получить дополнительные разъяснения по каждому этапу. При этом процессы формализации, регулирования и доверия взаимодействуют друг с другом.

\section{Автономия: выявление рисков}

Выявление рисков происходит на фоне ограниченной информации и осведомленности будущих партнеров при разработке проекта ГЧП.

\section{СолиАарность: распрелеление рисков и прибыли}

Теоретически в ГЧП/ЧФИ риски распределяются между теми участниками, которые лучше всего могут с этими рисками справиться. В договорном праве предполагается, что распределение рисков - это результат взаимодействия противоположных интересов сторон [2, с. 221-224]. Правовые нормы контракта между двумя партнерами содействуют активизации «усилий сторон, направленных на минимизацию рисков и их оптимальное распределение в [будущих непредвиденных] ситуациях» [3, с. 1089-1150]. Тем не менее, государство не всегда устраивает такое распределение рисков. Распределение рисков помогает не только определить, какая сторона является основным носителем рисков, но и найти способы, с помощью которых их можно было бы разрешить в рамках автономии. Однако будь то составление контракта, связанное с определенными рисками, или реализация ГЧП/ЧФИ - солидарность в любом случае необходима. Фактическая или договорная взаимозависимость между партнерами подразумевает, что дискреция одного влияет на другого, поэтому необходимо разработать способы решения этих последствий. Здесь вступает в силу управление рисками.

\section{Аоверие: управление и формализачия}

При долгосрочных контрактах высока вероятность возникновения непредвиденных обстоятельств, поэтому в контрактах прописываются не все условия, для них необходима особая гибкость. Чтобы в деловых отношениях существовали доверие и солидарность, нельзя допускать проявления оппортунизма. Управление рисками позволяет не допустить их исключительно формального распределения. На ранних этапах предполагалось, что как только стороны определят, какие риски будут переданы, частный подрядчик сможет управлять ими оптимальным образом в целях максимальной эффективности. SoPC4 и PF2 в равной степени подчеркивают, что необходимо избегать слишком частого вмешательства государства в управление рисками (например, при по- 
ставках товаров), которое может вызвать обратный эффект. Однако Национальное контрольно-ревизионное управление Великобритании (NAO) подчеркивает необходимость совместного решения проблем, что ведет к объединенному управлению [6, с. 5]. Следовательно, SoPC4 и PF2 предлагают различные способы укрепления сотрудничества между сторонами. На практике в управлении рисками существует распределение ролей между государственными и частными организациями: подрядчик (частный партнер) должен управлять рисками и передавать информацию государственному органу [9]. Обеспечению гарантий управления рисками способствует как документирование платежных процедур относительно достигнутых результатов [1, с. 31] так и налаживание каналов для поддержания надлежащего уровня управления рисками каждой из сторон. Тем не менее такое управление и контроль во время реализации ГЧП могут повлиять на выявление рисков и их распределение. Это происходит в рамках общего процесса формализации и укрепления доверия. На самом деле, доверие основано на внутреннем контроле и постоянной переоценке оснований для такого доверия. С помощью матрицы риска каждая сторона может установить, оправдано ли ее доверие другой стороне, проверить, соответствует ли пове- дение согласованным стандартам, убедиться, приложены ли максимальные усилия к достижению цели. Точно так же матрица риска может быть использована, если одна из сторон хочет показать свою надежность и добросовестность. Такая добросовестность имеет особое значение в проектах ГЧП на протяжении всего периода их существования. В моделях SoPC4 и PF2 этот вопрос рассматривается на примере нарушений сроков поставки. Так, если частный партнер предлагает приемлемые альтернативы, санкции могут быть смягчены [7].

Представляется, что с учетом рассмотренного международного опыта, выбор оптимального способа реализации инфраструктурного проекта должен базироваться на следующих принципах.

1. Принцип применения качественных критериев, позволяющих определять возможность применения и целесообразность использования механизмов ГЧП для конкретных инфраструктурных проектов.

2. Принцип применения количественных критериев оценки посредством сравнения чистых приведенных затрат бюджета с учетом поступлений и распределения рисков.

\section{ЛИТЕРАТУРА}

1. A Guide to Contract Management for PF1 and PPP Projects // Public Private Partnerships Programme. 2007.

2. Boyron S. The Public — Private Divide and the Law of Government Contracts: Assessing a Comparative Effort // The Public — Private Law Divide: A Potential for Transformation? / M. Ruffert (ed.). BIICL, 2009.

3. Goetz C., Scott R. Principles of Relational Contracts // Virginia Law Review. 1981. Vol. 67, no. 6.

4. Kerali H. Public sector comparator for Highway PPP Projects. URL: https://docplayer.net/12773754-Public-sector-comparator-for-highway-ppp-projects-henrykerali-lead-transport-specialist.html.

5. PFI: Strengthening Long-Term Partnerships // Treasury. 2006. March.

6. Risk Allocation Model for Project Strategy and Procurement / OGC, 2006; Best Practice: Risk Allocation in Long-Term Contracts / OGC, 2002; A risk management approach for partnerships // Managing Risks with Delivery Partners / HM Treasury, OGC, 2005.

7. SoPC4. Para 4.2.6; Standardisation of PF2 Contracts (draft). Para 8.2.6.

8. Standardisation of PF2 Contracts (draft) // Treasury. 2012. Para 7.9.5.

9. Technical Note no. 5 «How to construct a Public Sector Comparator» / TTPF, 1999. Para 4.8.3.

10. Белицкая А.А. Правовое обеспечение государственной инвестиционной политики: дисс. ...доктора юрид. наук. М. 2019.

11. Оценка эффективности проектов ГЧП по сравнению с иными формами реализации инфраструктурных проектов в странах — участницах ЕАЭС // http. www.cmokhv.ru

12. Собрание законодательства Российской Федерации от 20 июля 2015 г. № 29 (часть I) ст. 4350.

13. Собрание законодательства Российской Федерации. 25.07.2005. № 30 (ч. ІІ). Ст. 3126.

(c) Троценко Оксана Сергеевна ( trocenko.o@mail.ru ). 